\title{
Spall Fracture of Metallic Aluminum Induced by Penetration of Liquid Gallium-Indium Alloy and Moisture at Room Temperature
}

\author{
Mari Mizusawa and Kenji Sakurai* \\ National Institute of Materials Science (NIMS), Sengen, Tsukuba, Ibaraki, JAPAN
}

Fax: 81-029-859-2821, e-mail: sakurai@yuhgiri.nims.go.jp

\begin{abstract}
The present paper reports on brittle spall fracture of aluminum foil and sheet at room temperature. It was found that fairly rapid fracture takes place upon contact with liquid $\mathrm{Ga}_{83} \mathrm{In}_{17}$ alloy in the presence of moisture. A rapid increase in temperature was observed during the reaction. Observation in a different atmosphere clarified that moisture has a strong influence on the present fracture process, although the phenomena are basically correlated to embrittlement by liquid $\mathrm{Ga}_{83} \mathrm{In}_{17}$ alloy penetrating into the grain boundaries of aluminum polycrystals. The fine debris obtained through the spall fracture was identified as metallic aluminum, neither bulk oxides nor hydroxides.
\end{abstract}

Key words: grain boundary, liquid metal embrittlement, fracture; moisture effects

\section{INTRODUCTION}

As is well known, when liquid gallium penetrates the surface of metallic aluminum, it degrades the latter's mechanical properties $[1,2]$. Recently, the interfacial penetration of liquid gallium into the aluminum grain boundaries was demonstrated by synchrotron X-ray microscopy, including micro-tomography [3-9], transmission electron microscopy [10] and atomic-force microscopy [11]. Such penetration can be sometimes even used to illuminate the grain boundaries of aluminum alloys in scanning electron microscopy observation. [12]. Although the reaction proceeds in normal atmosphere, it does not take place at room temperature, because the melting point of gallium is $29.8^{\circ} \mathrm{C}$. It would be interesting, therefore, if it were possible to lower the reaction temperature so that no heating was necessary in order to maintain a fluid liquid state. Indium-doped-gallium alloy, which is promising as a contact material [13], forms eutectic at $15.7^{\circ} \mathrm{C}$ for $\mathrm{In}: \mathrm{Ga}=17: 83$. That is, the material is liquid at room temperature. In the present research, the penetration of indium-doped-gallium alloy rather than simple gallium metals was investigated, with particular consideration given to the influence of normal air and moisture. Extraordinary effects, such as spall fracture of the aluminum surface and rapid exotherm, are discussed later.

\section{EXPERIMENTAL}

The samples studied in this research are metallic aluminum foil $(\sim 15 \mu \mathrm{m} \mathrm{t})$ and sheet $(\sim 0.3 \mathrm{~mm} \mathrm{t})$, which were cut into $10 \times 10 \sim 30 \times 30 \mathrm{~mm}$ samples. The surface was rinsed with acetone before the experiments. Commercially available liquid $\mathrm{Ga}_{83} \mathrm{In}_{17}$ alloy (melting point $15.7^{\circ} \mathrm{C}$, Ultra-Pure Chemical Laboratory, Japan) was dropped on to the center of a glass substrate. The drop size was ca. $2 \sim 3 \mathrm{~mm}$ in diameter. Then, aluminum foil was placed on the drop and sandwiched with another glass plate. The penetration of liquid alloy into the foil was observed in different atmospheres: (i) vacuum
( $\sim 10^{-3}$ Torr), (ii) $\operatorname{Ar}(1 \mathrm{~atm})$, (iii) dried $\mathrm{N}_{2}$ gas (1 atm) and (iv) in air. For sheet samples, the alloy was simply dropped on to the sample. Heating tests were carried out in air. The samples were kept at 30,50 , and $70^{\circ} \mathrm{C}$ for $30 \mathrm{~min}$, respectively. For observation during the experiments, a normal optical microscope (Type SCZ, Carton), a metallurgical microscope (Olympus BX600), a scanning electron microscope (S-3100ST, JEOL, acceleration voltage $10 \mathrm{kV}$ ), and an X-ray powder diffractometer (RINT2500, Rigaku Corp., $\mathrm{Cu} \mathrm{Ka}$ radiation, $40 \mathrm{kV}-300 \mathrm{~mA})$ were employed. A thermocouple (type $\mathrm{K}$ ) and digital multimeter (Keithley 2000) were used for measuring the temperature increase caused by the spall fracture of aluminum.

\section{RESULTS AND DISCUSSION}

Fig. 1 shows the changes observed in the surface of aluminum foil that had been in contact with liquid $\mathrm{Ga}_{83} \mathrm{In}_{17}$ in a vacuum for $1 \mathrm{~h}$ and then exposed to air. While no significant changes were apparent while in the vacuum, exposure to air caused an abrupt change. In most cases, the alloy penetrated from the back and the color of the aluminum surface became non-metallic, i.e., gray, in a few minutes after exposure to air. The changes proceeded in the following way: first, the center became gray, then the outer region started to change, and finally, the intervening region, i.e., between the center and outer region, gradually changed. These distorted regions did not recover and did not exhibit additional changes even after a considerable time had elapsed. The results were quite similar in an $\mathrm{Ar}$ or $\mathrm{N}_{2}$ environment. The color of the aluminum surface did not change, but some roughening was visible around the region where the $\mathrm{Ga}_{83} \mathrm{In}_{17}$ alloy was dropped. As soon as the sample was exposed to air, the surface changed dramatically. The gradual changes continued for a number of hours, and finished after ca. $7 \mathrm{~h}$. As shown in Fig. 2, the area that underwent a color transformation is formed around the small residue of $\mathrm{Ga}_{83} \mathrm{In}_{17}$ alloy, which was located almost at the center of the aluminum 

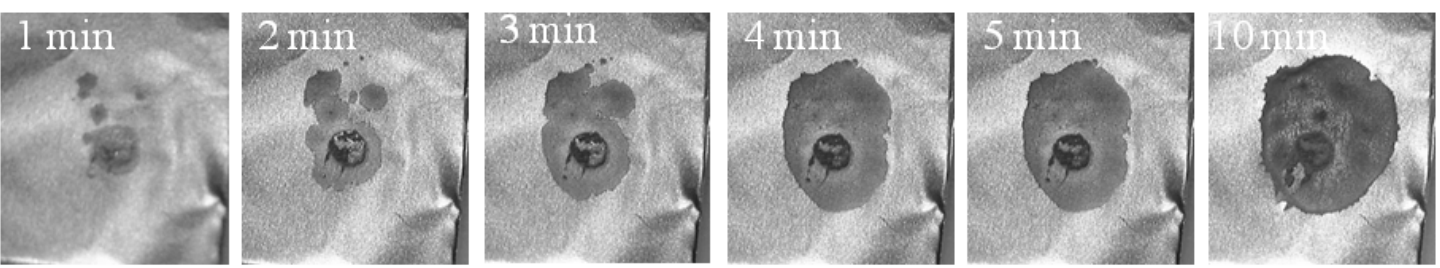

Fig. 1 Optical microscope observation of embrittlement in aluminum. Liquid $\mathrm{Ga}_{83} \mathrm{In}_{17}$ alloy was dropped onto an aluminum surface in a vacuum $\left(\sim 10^{-3}\right.$ Torr $)$ and kept for $1 \mathrm{~h}$. Then, the sample was exposed to the air. The series of photos was taken immediately after such exposure.

foil. One can see a dark-gray angled belt, which corresponds to the outer edge of the initial rapid invasion of $\mathrm{Ga}_{83} \mathrm{In}_{17}$ alloy. The diffused border is caused by subsequent slow changes.

In contrast, some differences in the final states were observed when contact was made in air. In particular, much depends on the humidity. For the $25 \times 25 \mathrm{~mm}$ aluminum foil, a complete color change was observed for almost the whole surface (not shown here), but the dark-gray belt shown in Fig. 2 did not appear.

Fig. 3 shows the observation of the effect of heating in air on the surface of the aluminum foil in contact with liquid $\mathrm{Ga}_{83} \mathrm{In}_{17}$. During heating, the color was almost the same, even in air, but changed rapidly once heating stopped. The extension of the gray area was dependent on the temperature. The size for the sample kept at $70^{\circ} \mathrm{C}$ was much larger than that for $30^{\circ} \mathrm{C}$. This indicates that heating facilitates the diffusion of liquid $\mathrm{Ga}_{83} \mathrm{In}_{17}$ in aluminum, while fracturing does not occur in this case. Cessation of heating and then cooling to room temperature causes similar effects to removing the sample after keeping it in a vacuum or in $\mathrm{Ar}$ or $\mathrm{N}_{2}$ gases. In the early stage of this research, some oxidation of the surface was considered as the origin of the color changes,
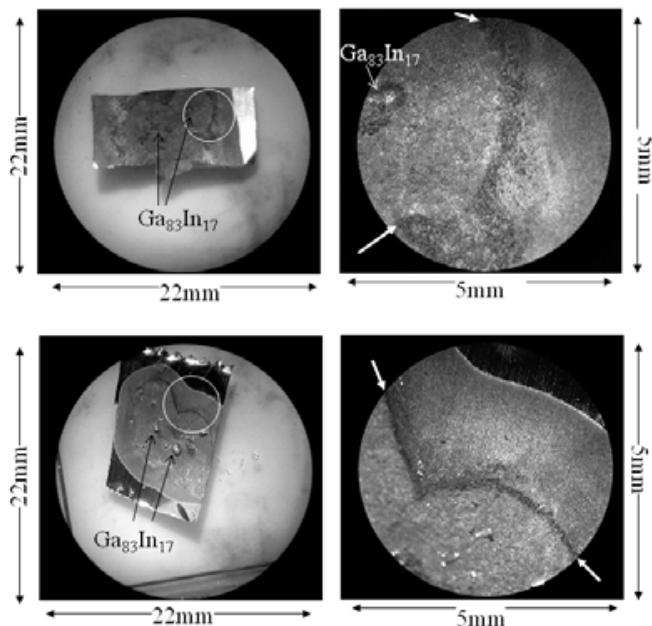

Fig. 2 The effect of atmosphere in embrittlement of aluminum. Liquid $\mathrm{Ga}_{83} \mathrm{In}_{17}$ alloy was dropped onto an aluminum surface in an $\mathrm{Ar}$ (a) or $\mathrm{N}_{2}$ (b) atmosphere and kept for $1 \mathrm{~h}$. Then, the sample was exposed to air. The photos were taken after $7 \mathrm{~h}$ under an optical microscope in air. The right-hand photos are enlargements of the circled areas in the left-hand photos. The dark gray belt was formed in the initial abrupt reaction just after exposure to air. As indicated by the arrows, one can see that the borders of the belt are quite diffused, which correlates to the reaction slowing down. but the results indicate that this is not true.

Therefore, in the present research, the influence of moisture in air was examined. First, it was found that keeping the sample in a drier was effective in suppressing the reaction. The color of the aluminum foil did not change even in air, in a manner similar to an atmosphere of $\mathrm{Ar}$ or $\mathrm{N}_{2}$ gases. Second, generally, the sample becomes brittle simply by lowering the temperature to the solidification point of $\mathrm{Ga}_{83} \mathrm{In}_{17}$ alloy. However, we did not find any apparent quick changes when the sample was put into liquid nitrogen. This is due to the absence of moisture. Third, water was directly instilled on to the sample in order to thoroughly ensure the impact of moisture. Fig. 4 shows the drastic fracture of aluminum sheet metal following the instillation of water. The residue of $\mathrm{Ga}_{83} \mathrm{In}_{17}$ alloy was removed before instillation. Within $30 \mathrm{sec}$ after dropping on the water, bubbles were seen, and the sample was inflated, and fractured. The gray area, which is caused by the erosion of $\mathrm{Ga}_{83} \mathrm{In}_{17}$ alloy, spread during contact, but the border was not blurred. Absorbing water induces rapid spall fracture and the aluminum foil or sheet can be broken into fine powders. Such a change can be observed several seconds after instillation. Even in an $\mathrm{Ar}$ atmosphere, almost the same results were obtained. We attribute this to the penetration of water into the grain boundaries that were expanded with $\mathrm{Ga}_{83} \mathrm{In}_{17}$ alloys. Almost the same phenomena were confirmed when methanol was applied. However, hexanes did not have any affect at all. Probably, the polarity of the solvent affects the
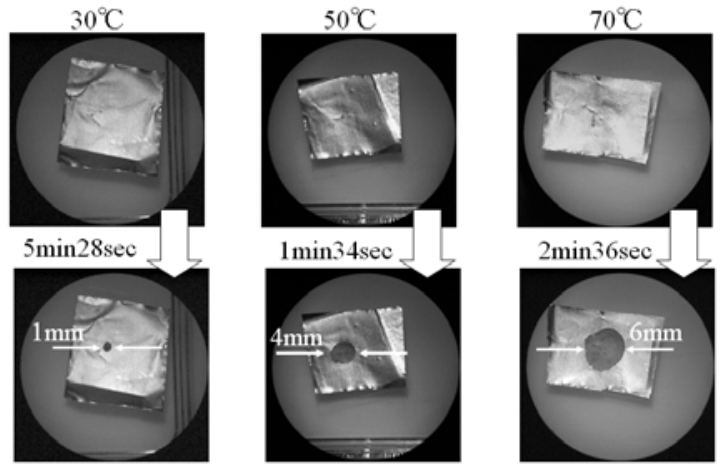

Fig. 3 Effect of heating in embrittlement of aluminum. Liquid $\mathrm{Ga}_{83} \mathrm{In}_{17}$ alloy was dropped onto an aluminum surface in air at various temperatures $\left(30^{\circ} \mathrm{C}, 50^{\circ} \mathrm{C}\right.$ and $70^{\circ} \mathrm{C}$ ). The sample was placed on the hot plate, and kept for $30 \mathrm{~min}$. Cooling then started by switching off the heater, and the upper photos were taken immediately after that, and after some delay, the lower photos were captured. 

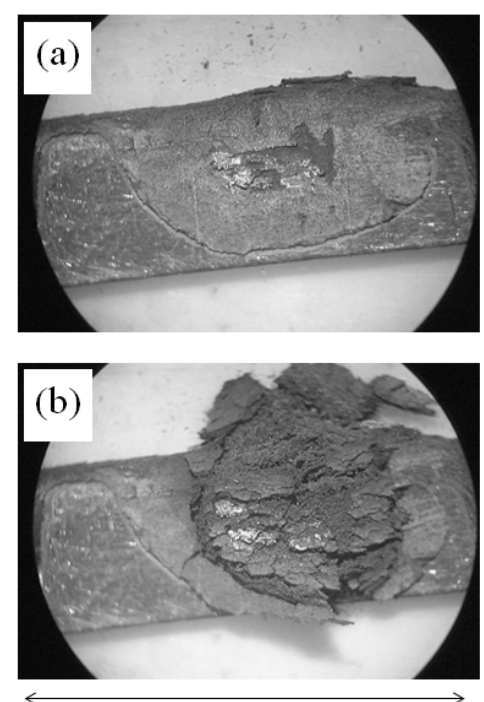

$12 \mathrm{~mm}$

Fig. 4 (a) Brittle texture of aluminum formed by contact with $\mathrm{Ga}_{83} \mathrm{In}_{17}$ alloy and by exposure to air. The surface color of the area invaded by $\mathrm{Ga}_{83} \mathrm{In}_{17}$ alloy changed. (b) Spall fracture of aluminum by dropping water onto the brittle texture shown in (a).

penetration of the grain boundaries. Fourth, surface modification could affect the reaction with moisture in air. One possible way of averting such erosion of the $\mathrm{Ga}_{83} \mathrm{In}_{17}$ alloy would be to prepare an oxide layer on the upper surface. It was confirmed that an anode oxidation film made in $0.1 \mathrm{M} \mathrm{H}_{2} \mathrm{SO}_{4}$ at $10 \mathrm{~V}$ for $10 \mathrm{~min}$ is effective, and no special change was observed even when the sample was placed in contact with liquid $\mathrm{Ga}_{83} \mathrm{In}_{17}$ alloy in air.

In order to further investigate the influence of water on embrittlement, an aluminum foil in contact with $\mathrm{Ga}_{83} \mathrm{In}_{17}$ alloy for $22 \mathrm{~h}$ was placed in water. Fine fractions were sampled from the precipitated materials, and dried in air. Fig. 5 (a) shows a SEM image of typical fragments that fractured rapidly from aluminum foil through the addition of water. One can see strip-like fragments of around $1 \times 10 \mu \mathrm{m}^{2}$, which are covered with small triangular flakes up to $12 \mu \mathrm{m}$. In contrast, when aluminum sheet was used instead of foil, the size distribution of the fractured fragments ranged widely from $0.1-100 \mu \mathrm{m}$, and the fragments were typically flake-like. This is because the aluminum was broken only along the direction of rolling and was not torn into isolated grains. In addition, as shown in Fig. 5 (b), the fragments exhibit an X-ray powder pattern corresponding to metallic aluminum. This indicates that, because of the reaction, aluminum oxides and hydroxides are only on the surface, not inside the grains. In addition, the peaks from gallium, indium and their oxide were not observed in this case. The amount of $\mathrm{Ga}_{83} \mathrm{In}_{17}$ alloy absorbed at the boundaries was not so significant.

Another important fact is that the spall fracture of aluminum is exothermal. Fig. 6 shows the results of temperature measurements of the water held in a vial with a piece of aluminum metal. The vial is held in a thermal insulator, and the initial temperature was kept at $20{ }^{\circ} \mathrm{C}$. $\mathrm{Ga}_{83} \mathrm{In}_{17}$ alloy was placed on the aluminum sheet for two hours before instilling the water. As shown in Fig.6, the water temperature can be typically raised higher than $25{ }^{\circ} \mathrm{C}$, although this obviously depends on the given amount of water, when the aluminum metal is added. We observed that the given amount of water could even become steam when the amount is reduced to $1 \mathrm{ml}$ or less. The rise in temperature is due to the energy release of the chemical bonding at the grain boundaries as solid bulk during its drastic breakdown into micrometer-sized fractions.

It has been suggested that water has a crucial influence on spall fracture. Such a drastic reaction was not observed in experiments using pure metallic gallium. One should note the differences in the wetting nature of liquid gallium and $\mathrm{Ga}_{83} \mathrm{In}_{17}$ alloy with respect to a solid aluminum surface. While liquid gallium is likely to be aggregated, liquid $\mathrm{Ga}_{83} \mathrm{In}_{17}$ alloy has a much smaller angle of contact and therefore spreads over the surface very easily $[14,15]$. The penetration into the grain boundaries of aluminum is easier for liquid $\mathrm{Ga}_{83} \operatorname{In}_{17}$ alloy than for liquid gallium. The existence of a large amount of water can cause the formation of some oxides and/or hydroxides at the grain boundaries, which are filled with liquid $\mathrm{Ga}_{83} \mathrm{In}_{17}$ alloy spreading along the interfaces. Because of volume expansion through solidification and/or formation of oxides/hydroxides (although the total amount would be very small to detect by X-ray diffraction), spall fracture of aluminum can
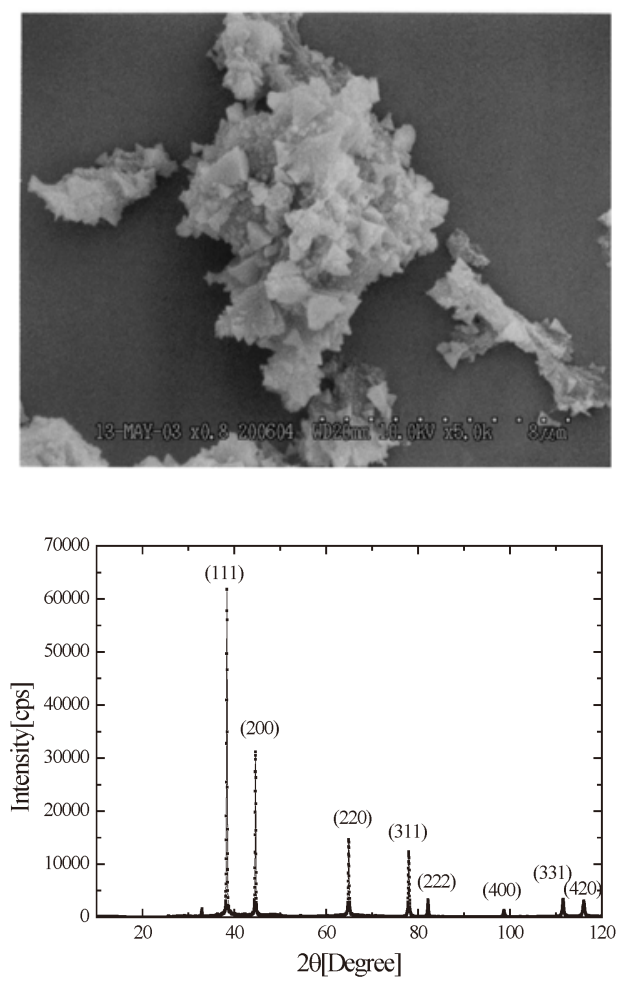

Fig. 5 (a) SEM image of the aluminum fraction obtained by adding water to foil that has been in contact with $\mathrm{Ga}_{83} \mathrm{In}_{17}$ alloy for $22 \mathrm{~h}$ in air. The white dotted line shows the scale as $8 \mu \mathrm{m}$. (b) X-ray diffraction pattern of the aluminum fraction. Indexes of metallic aluminum are shown. A small peak at $32.9 \operatorname{deg}(\mathrm{d}=2.719 \AA)$ is not from aluminum, and is close to $(-202)$ reflection of $\mathrm{Al}_{2} \mathrm{O}_{3}(\mathrm{~d}=2.7295 \AA)$. 


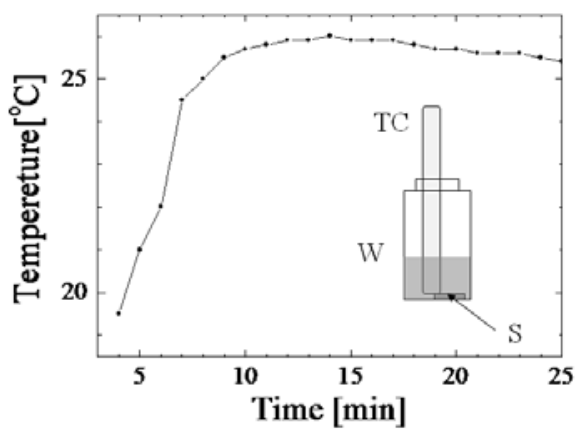

Fig. 6 Measurement of temperature increase during the spall fracture of aluminum. TC: thermo-couple gauge, $\mathrm{W}$ : water and $\mathrm{S}$ : sample (aluminum sheet or foil embrittled by $\mathrm{Ga}_{83} \mathrm{In}_{17}$ alloy).

take place. The phenomena found in the present research are unique for a combination of $\mathrm{Ga}_{83} \mathrm{In}_{17}$ alloy and metallic aluminum. This is simply due to penetration being much more rapid compared with liquid gallium.

As for the much slower reaction with normal levels of moisture that are present in air, instead of the intentional addition of water, it is worthwhile mentioning the change in morphology. Metallurgical microscopic observation in air revealed that there are two successive steps in the change to the gray area; (i) it extends along the grain boundaries, polishing scratches, and direction of rolling, and then becomes dark but remains flat, and (ii) it is raised up like a scale, and the surface becomes rough. Since the second step takes place right after the first step, the gray area remains flat around the borders. The mechanical and electrical properties also changed substantially. The sample appeared to lose both strength and good conductivity, indicating that the aluminum foil became brittle and that the surface was split into micro particles. The moisture can induce a remarkable spall fracture just because of such a brittle texture.

In summary, spall fracture of metallic aluminum foil and sheet were studied. Liquid $\mathrm{Ga}_{83} \mathrm{In}_{17}$ alloy can penetrate into the grain boundaries of aluminum, and break the texture into fine fragments rapidly in the presence of water. The reaction is exothermal and can heat its ambience.

\section{ACKNOWLEDGMENTS}

This work was partly supported by the Active Nano-Characterization and Technology Project, Special Coordination Funds of the MEXT, Japanese Government.

\section{REFERENCES}

[1] W. Rostoker, J. M. McCaughey and H. Markus, "Embrittlement by Liquid Metals", New York, Rheinhold Pub (1960).

[2] M. G.. Nicholas and C. F. Old, J. Mater. Sci, 14, $1-18$ (1979).

[3] W. Ludwig and D. Bellet, Mater. Sci. and Eng., A281, 198-203 (2000).

[4] W. L. Tsai, Y. Hwu, C. H. Chen, L. W. Chang, J. H.
Je, H. M. Lin and G.. Margaritondo, Nucl. Instrum. \& Meth., B199, 457-463 (2003).

[5] E. Pereiro-Lopez, W. Ludwig and D. Bellet, Acta Mater, 52, 321-332 (2004).

[6] W. Ludwig, E. Pereiro-Lopez and D. Bellet, Acta Mater., 53, 151-162 (2005).

[7] T. Ohgaki, H. Toda, I. Sinclair, J.-Y. Buffiere, W. Lutwig, T. Kobayashi, M. Niinomi, and T. Akahori, Materials Sci. \& Eng. A406, 261-267 (2005).

[8] E. Pereiro-Lopez , W. Ludwig, D. Bellet, P. Cloetens, and C. Lemaignan, Phys. Rev. Lett., 95, 215501 (2005).

[9] M. Kobayashi, H. Toda, K. Uesugi, T. Ohgaki, T. Kobayashi, Y. Takayama, and B.-G. Ahn, Philo., Mag., 86, 4351-4366 (2006).

[10] R .C. Hugo and R. G. Hoagland, Acta Mater., 48, 1949-1957 (2000).

[11] R. Tanaka, P-K. Choi, H. Koizumi and S. Hyodo, Mater. Trans. JIM, 41, 138-140 (2001).

[12] .J. Hagstrom, O. V. Mishin and B. Hutchinson, Scripta Mater., 49, 1035-1040 (2003).

[13] E. Gmelin, M. Asen-Palmer, M. Reuther and R. Villar, J. Phys. D: Appl. Phys., 32, R19-R43 (1999).

[14] T. Tanaka, M. Matsuda, K. Nakao, Y. Katayama, D. Kaneko, S. Hara, X. Xing and Z. Qiao, Z. Metallkd, 92, 1242-1246 (2001).

[15] M. V. Trenikhin, A. V. Bubnov, A. I. Nizovskii, and V. K. Duplyakin, Inorg. Mater., 42, 256-260 (2006).

(Received July 14, 2009;Accepted Septmeber 24, 2009) 